\title{
Outstanding Female Leadership in Implementing Effective School
}

\author{
Susan Febriantina \\ Universitas Negeri Jakarta: Faculty of Economy \\ Jakarta, Indonesia \\ susanfebriantina@unj.ac.id
}

\begin{abstract}
We studied female leadership style combined with skills in implementing effective school to investigate phenomenon by using qualitative case study method. The result are female principal uses many styles in leading effective school, such as interactive, transformational, democratic/participative, authoritarian, and situational style within motherly approach. Moreover, we found the uniqueness of her leadership are the combination of motherly leadership approach with some skills included technique, human interpersonal, and conceptual. These uniqueness become added factors to support outstanding female leadership in implementing effective school todays. Our finding result of an outstanding female leadership may be used for any kind school leaderships nowadays.
\end{abstract}

Keywords-female leadership; style within motherly approach, skill

\section{INTRODUCTION}

In recent years, strategies for empowering female leadership in effective school has been burgeoning interest. However these strategies have not been so impact on increasing female principals number, especially in Indonesia. [1] Based on data from Indonesian Education and Culture Department, the number of female teachers is $53 \%$ out of total teachers. But, female principal at senior high school are less than $13 \%$ out of principals total number in Indonesia from 2005 to 2010. [2] Thus, the disparities due to the role and position of women in leadership especially in educational institution is still happening. [3]

This condition is often linked with women vulnerability in leading educational institution. [4] Obviously, this is not because women are less effective in leading educational institution, if women have a leadership advantage, they might show up in effective leadership styles that diverge somewhat from those that are typical of their male colleagues. [5]

Among less number of female principals in Indonesia, there is one female principal who inspires educational leadersip. Having regard to these points, the way of outstanding female principal leadership in supporting her followers, making decision, and solving the problems using her motherly approach, style and skills are very interesting to be studied. The study aims to investigate phenomenon its real-life situations and detailed analyses of the problems. [6]

\section{STATE OF THE ART}

Previous research focus on which one the most effective between men and women leadership generally. [7] Some discussed about women tended to adopt a more democratic or participative style and a less autocratic or directive style than did men. [8] Another study measured the extent to which the attitude and perception of teachers towards women principals in comparison to men principals. [9]

The weaknesess of those studies are not focusing on female leadership style and skills which become important factors in managing effective school. In our study, we focus on these issues.

\section{PROBLEM STATEMENT}

Our focus in this research is outstanding female leadership in implementing effective school. Because of the circumstances of this research, the sub focus of this research is limited into two aspects, they are; (1) female principal leadership style; and (2) female principal leadership skills.

\section{PROPOSED APPROACH}

The study conducted in 2011 until 2012 at senior high school 3 in Depok, Indonesia, where its principal was an outstanding female principal in Indonesia. The data collected from four sources, namely direct observation, participant observation, interview, archieve and documentations. [10] In direct observations we observed the way she motivates her followers, makes decision, and solves the problems. We also observed her skills included technical, interpersonal and conceptual skills in implementing effective school. Besides, we also observed school organizational structure, school systems, bureaucracy, and administration mechanism, which those are related to female principal's styles and skills. Another thing that is not less important is that we could sense and directly observe principal's behavior as well as study the response of each follower. [11]

We also did unstructured and structured interview to 30 professional teachers and administration staffs, 10 students, an outstanding female principal, a school supervisor from Depok Education Department of and the Head of Depok City Education Department. In getting unstructured interviews we began with global interview, and simply outlines to be asked. Then we did structured interviews which conducted with more directives. It 
means that the implementation of the interview more dominated by the views and guidelines that had been developed at previous interview. In structured interviews, we asked issues related to school leadership that includes the way of female principal's motivating, decision-making, and problem solving. [12]

Technically, we conducted structured interviews with several steps: first, we began by making a list of informants to be interviewed from key informants and the results of previous observations. Second, we met the informant one by one and introduced self. Third, we asked permission and willingness to do the interview to them. Fourth, after the informant agreed to be interviewed, we made appointment with the informants related to the time and place of the interview that is adapted to the ability of informants. In addition, we also provided a summary of the research proposal to the informant in order to better understand. Fifth, the day before the interview was conducted, we contacted the informant by phone and prepared everything for the implementation of the interview. Sixth, at the time of the interviews, we proposed several research questions in accordance with the guidelines previously prepared. In answering to the questions of our research topic, some informants gave answers that were not fit with the research focus and sub focus, but we still recorded it as a finding. Seventh, at the time of the interview, we recorded all the interviews through a digital camera and record the important things. Eight, after the interview is completed, we wished to thank and asked the informant's willingness to call back if we still need more information and data in the future. Ninth, we applied to borrow some related documents during the interview to the informants. We also collected and studied some documents. These documents included school program, the implementation of the program, achieved evidences and school reports. [13]

In analysing the data, we used three process, named reduction, display/presentation and verification/conclusion. In reducting data, we looked cores or subjects from data that are considered important in every aspect of the study's findings. In displaying data, we created a narrative summary and systematic, so the focus theme can be seen easily. Then, we gave intent on each summary with regard to the suitability of the materials research. Next, we verified data by constantly rechecking the processes, comparing the results of observations, interviews, documentation study and doing triangulation. Our conclusions are correlated with relevant theories. Finally, we did verification as a result of the research. [14]

To establish the legitimacy (trustworthiness) of data, we required examination technique which is based on four criteria, credibility, transferability, dependability, and conformability First, our credibility is done by longer participation in the field, finding similarities of data cycles, perseverance observations in the field, doing data triangulation (researchers, methods, theories, and data sources triangualtion), checking all discussion with the colleagues, having added references such as video, images, recorded interviews, and daily records during the field, making detailed description, and checking the data dependability and reliability. Second, to obtain the transferability, we collected empirical incidence of the common context. We reported the results of studies that describe the subject matter with the data in the field and review of literature. Third, dependability test was done by checking every activity in the field through field notes on the observation. Moreover, to provide the data consistently, we consulted with the supervisor, peers as well as some leaders and practitioners in the community. The last, we did conformability by recapitulating collected raw data, compiling selected analyses results, making synthesis, making interpretations and conclusions of the study, and reporting research mechanism as a whole in order to prove that this finding is indeed a reality. [15]

\section{CONCLUSION AND FUTURE WORK}

Our results identify an important component of the outstanding female leadership. In implementing effective school, female principle combined several styles of leadership within skills. The styles involved interactive, transformational, democratic/participative, authoritarian, and situational style in motivating subordinates, making decisions and solving the problems. All leadership styles combined by motherly approach. We find her interactive style in motivating subordinates. The way she motivates her folowers dominantly used motherly approach such as attentive, caring, fair, gentle, loving, reinforcing others, preferred share, and being a model for her follower's goodness. The ways she motivates followers are believed to be more selfless and concerned with others; more kind, helpful, understanding, warm, sympathetic, and aware of other's feeling. Moreover, she is also strong on motivating others, fostering communication, listening, mentoring, and supporting highquality work. In motivating followers, female principal also gives full of confidence and positive appreciation to her followers, then she is positioning herself as a mother and friend for all her followers. She also always says "please", "sorry" and smile when she motivates her followers. The ways she did makes her followers feel well treated by their "mother", in fact she is their leader. In making decision and solving the problems, female principal uses democratic/participative style. She involves related stakeholders such as vice-principal, teachers, staff, school committees, community leaders and in certain case also students through discussions, shares, and meetings. However, in some cases, her decision making is regarded wastes long time because she needs to discuss with any related stakeholders. We also find that transformational leadership style dominantly seen. As a leader of change, female principal make new breakthroughs in motivating subordinates. Her phenomenal's change is making a convenient school infrastructure, includes green school concept. These changes impact on folower's performance increasing student's achievements. In facing uncertainty and challenges, female principal convinces followers to make preventive measures and anticipatory even in the worst conditions. As a 
visionary, she make a clear school vision, mission and strategy which are understood by all school communities. Authoritarian style is also occasionally used by female principle for example when faces disobedient and undisciplined followers. In such conditions, female principal with her authority as a leader uses her authority to warn, even punish them. This does not make her leadership ineffective because one of the logical consequences of this reality is that styles she uses are not entirely used simultaneously but adapted with situations. The more that leaders can adapt their behaviors to the situation, the more effective their attempts' to influence become.

Female uniqueness skills includes three skills, they are technical, interpersonal, and conceptual skill. Female principal technical skills are developing school infrastructure, managing the beauty and cleanliness of school environment and school finance, managing school community discipline, making decisions and determining priorities in implementing policy. Her technical skills are gained through experience, education and training. Interpersonal skills could be seen when female principal communicates with various parties including followers, students, school committees, local governments, and even the public. She also successfull creates high kinship and social awareness, sympathy and empathy among school community. Other her interpersonal skills are the ability of public speaking, doing successfull diplomacy with public, establish good relationship with many people, build school team work, set school community's differences, and provide excellet service for school customers. By interpersonal skills, female leadership may tend to be particularly suited to middle managerial roles. We can see female principle's conceptual skills dominantly in making, aranging and developing school vision, mission and strategy. Her best featured programs such as Green Community, Clinical Study, Excellent Service, and Foster Teacher make school different from other public schools. Our results will have important policy implications. The chances to be school leader open wider for women, then it may increase female's motivation in doing their best and potentials. More generally, our results improvee the ability of female leader to break through the glass ceiling and attain top leadership positions which has positive externalities for other women. We propose a broader and potentially more pervasive mechanism: Female leaders can redirect the characteristics and cultures.

\section{REFERENCES}

[1] M. Budianta, "Plural identities: Indonesian women's redefinition of democracy in the post-Reformasi era" RIMA: Review of Indonesian and Malaysian Affairs, Vol. 36, No. 1, 2002: 35-50

[2] The Central Bureau of Statistics Ministry of Indonesia National Education, 2005-2010

[3] J. E. Sanchez and B. Thornton, "Gender Issues in K-12 Educational Leadership," Advancing Women in Leadership Journal, vol. 30, no 13, p. $1-15,2003$

[4] Robin G. Isserles, "Microcredit: The Rhetoric of Empowerment, the Reality of "Development As Usual", Women's Studies Quarterly. Vol. 31, No. 3/4, Women and Development: Rethinking Policy and Reconceptualizing Practice (Fall - Winter, 2003), pp. 38-57
[5] Hudson and Dorothy Rea, "Teachers' Perceptions of Women In The Principalship, A Current Perspective" AWL Journal Vol, No 3, pp.1-4 Summer, 1998

[6] Bent Flyvbjerg, " Five Mistakes Misunderstandings Abput case Study Research", Qualitative Inquiry April 2006 vol. 12no. 2219-245, http://qix.sagepub.com/content/12/2/219.short

[7] A. H. Eagly \& L. L. Carli, "The female leadership advantage: An evaluation of the evidence," Leadership Quarterly, vol 14, pp. 807-834, 2003

[8] G. W. B. Sharpe, "Principalship and Gender A Case Study, Theoretical Analysis, and Applied Policy Implications," American International Journal of Contemporary Research, Vol.1, no 2, pp. 38-43, September 2011

[9] A. H. Eagly and B. T. Johnson, "Gender and Leadership Style: A Metaanalysis," Psychological Bulletin, Vol. 108, No. 2, pp. 233-256, 1990

[10] R. K. Yin, Case Study Research: Design and Methods. London : Sage Publication, Inc, 1994

[11] Kratochwill, T. R., Hitchcock, J., Horner, R. H., Levin, J. R., Odom, S. L., Rindskopf, D. M \& Shadish, W. R. "Single-case designs technical documentation. Retrieved from What Works Clearinghouse" http://ies.ed.gov/ncee/wwc/pdf/wwc_scd.pdf, 2010

[12] Pat Croskerry, "From Mindless to Mindful Practice - Cognitive Bias and Clinical Decision Making" Engl J Med 2013; 368:2445-2448 June 27, 2013

[13] Bogdan, Robert C. and Biklen. Sari Knopp. Qualitative Research for Education; An Introduction to Theories and Methods. USA: Pearson Education, Inc, 2007

[14] Garry Thomas, "A Typology for the Case Study in Social Science Following A Review of Definition, Discourse, and Structure" Qualitative Inquiry July $2011 \mathrm{vol} . \quad 17 \quad$ no. $\quad 6511-521$ http://qix.sagepub.com/content/17/6/511.short

[15] Daniel W. Turner, III, "Qualitative Interview Design: A Practical Guide for Novice Investigators" The Qualitative Report Volume 15 Number 3 May 2010 754-760 http://www.nova.edu/ssss/QR/QR15-3/qid.pdf 